\title{
Effects of physical activity and smoking on cardio-ankle vascular index, respiratory muscle strength, and exercise performance in early normal weight adulthood: a cross-sectional study
}

\author{
Tharnwimol Inthachai ${ }^{1 * *}$, Kanokwan Demekul ${ }^{2}$, Napaporn Phonsatsadee' ${ }^{1}$ Pannatorn Puttitommagool', Nontarat Boonyachart' \\ 'Department of Physical Therapy, Faculty of Allied Health Sciences, Naresuan University, Phitsanulok, Thailand \\ ${ }^{2}$ Department of Cardio-thoracic Technology, Faculty of Allied Health Sciences, Naresuan University, Phitsanulok, Thailand
}

Few studies have shown the impact of unhealthy habits on arterial stiffness, respiratory muscle strength and exercise performance in early normal weight adulthood. This study sought to determine the effects of physical activity and smoking on its parameters in normal weight male participants. Forty-eight participants were divided into four groups: physically inactive nonsmokers and smokers and physically active nonsmokers and smokers ( $n=12$ in each group). All of the participants were measured for body composition, arterial stiffness, respiratory muscle strength and exercise performance. Two-way analysis of variance design was used to test the main and interaction effects of physical activity by group (smokers vs. nonsmokers). $P$-value of less than 0.05 was considered as a statistically significant difference. As a result, cardio-ankle vascular index and respiratory muscle strength were diminished in smokers and physically inactive participants, while body and visceral fat mass were increased in both those groups. Fat-free mass was lower in only physically inactive participants. This study also found the interaction effects on body fat and arterial stiffness. In conclusion, participants with healthy normal weight, but smoked and performed inappropriate physical activity, exhibited body composition imbalance, decreased respiratory muscle strength, exercise performance, and increased arterial stiffness. Therefore, smoking cessation and exercise in younger adults are appropriate ways of improving body composition, respiratory muscle strength, aerobic capacity and arterial stiffness instead of trying to control their weight by smoking.

Keywords: Physical inactivity, Smoking, Arterial stiffness, Respiratory muscle strength, Exercise performance

\section{INTRODUCTION}

A growing financial crisis worldwide has caused an economic downturn in developing countries, thus causing people to work harder and have little time to take care themselves. This leads to increased risk of health problems (Mucci et al., 2016). Technology provides a quicker and easier way to live, but also gives less chance to participate in physical activities (Sullivan and Lachman, 2017). Furthermore, tobacco smoking is associated with multiple health problems and has become a public health concern (Fu et al., 2017). Approximately 5 million of 2.3 billion smokers die globally each year from smoking. Mortality and morbidity from smoking are predicted mainly in developing countries (Fu et al., 2017).

Adapting to life changes and alterations in a new society, participating with peer group activities, living outside the comfort of home, interconnecting with new friends and getting involved in the workforce are the causes of smoking in young adults (Tombor et al., 2015). Most smokers often smoke in the belief that it helps them to control their weight by increasing the metabolic rate, decreasing metabolic efficiency or reducing appetite, and ceasing to smoke causes weight gain (Chiolero et al., 2008). Cigarette smokers in early adolescence find it difficult to stop smoking, due to
${ }^{*}$ Corresponding author: Tharnwimol Inthachai

(iD https://orcid.org/0000-0002-0581-8480

Department of Physical Therapy, Faculty of Allied Health Sciences, Naresuan

University, 99 Moo 9, Tha Pho, Mueang, Phitsanulok 65000, Thailand

E-mail: tharnwimoli@nu.ac.th

Received: October 4, 2019 / Accepted: November 21, 2019
This is an Open Access article distributed under the terms of the Creative Commons Attribution Non-Commercial License (http://creativecommons.org/licenses/by-nc/4.0/) which permits unrestricted non-commercial use, distribution, and reproduction in any medium, provided the original work is properly cited. 
physiological changes and symptoms from tobacco-related diseases clearly disappear. Young smokers are a vulnerable group that is unwilling to quit the habit (Chiolero et al., 2008). As a consequence, education on smoking and how to control weight should target young adults (Wee et al., 2001).

In noninvasive measurements of arterial stiffness (AS), cardio-ankle vascular index (CAVI) may detect early phases of atherosclerosis, and work as a predictor of AS, morbidity, and mortality from cardiovascular diseases (CVD) (Sun, 2013). Although the prevalence of CVD is lower in young adults, it has been increasing in children and adolescents, who smoke and have less physical activity. Early detection of coronary artery disease (CAD) is important because vulnerable individuals such as asymptomatic young adults are more likely to experience cardiac events and later detection of subclinical coronary atherosclerosis (Toth, 2008). The circulatory and respiratory systems help to accomplish daily routines efficiently (Hautala et al., 2009). Respiratory muscle plays an important role in the cardiorespiratory system. A decline of inspiratory muscle causes impairment of physical fitness and quality of life, especially with increased risk of CVD (van der Palen et al., 2004). Therefore, providing knowledge and promoting good health in early years are important in avoiding health problems and improving adult quality of life (Frech, 2014).

Many studies have demonstrated the association of a sedentary lifestyle and higher body mass index (BMI), overweight and obesity with a greater risk of CVD (Mainous et al., 2019; Yadav et al., 2017). Nevertheless, smokers of all ages, particularly in early adolescence or less than 30 years, smoke in the belief that it helps them to control their weight (Wee et al., 2001). Few studies have demonstrated that physical inactivity and smoking in young adolescents with healthy weight has effect on AS, respiratory muscle strength and exercise performance. Therefore, this study aimed to determine the effect of smoking and physical activity on its parameters in physically active and inactive smokers and nonsmokers aged 20-30 years in order to improve understanding and promote the importance of exercise and smoking cessation.

\section{MATERIALS AND METHODS}

\section{Subject enrollment}

A total of 48 male participants were recruited into this study, which was carried out in accordance with the Declaration of Helsinki and approved by the Naresuan University Institutional Review Board (IRB No. 0132/62), at the Department of Physical Therapy, Naresuan University. The effect of sample size was deter- mined based on a previous study (Thitiwuthikiat et al., 2017). The calculation was carried out with $\alpha=0.05$ and $90 \%$ power. All of the participants were informed by the researchers about the aims, methods, and consequences of this study and they were free to decide whether to participate or not.

A cross-sectional study design with comparison of variables across four groups of participants was employed for this study. The 48 male participants, aged 20-30 years, were divided equally into four groups ( $\mathrm{n}=12$ in each group) based on the inclusion and exclusion criteria as follows: physically active male nonsmokers and smokers with normal BMI (18.5-22.9 kg/m², $\mathrm{n}=12$ per group), aged 20 to 30 years, who performed moderate or vigorous intensive exercise for more than 30 min, 5 days per week or more than 25 min, 3 days per week (Oja and Titze, 2011); and physically inactive male nonsmokers and smokers with normal BMI (18.5$22.9 \mathrm{~kg} / \mathrm{m}^{2}, \mathrm{n}=12$ per group), who performed moderate or vigorous intensive exercise for less than $30 \mathrm{~min}, 5$ days per week or less than 25 min, 3 days per week were enrolled into this study by using the International Physical Activity Questionnaire (Lee et al., 2011). Smokers who had smoked on $25-30$ days per month for at least 1 year, or nonsmokers who had not smoked before also were included in this study (Pulvers et al., 2014).

The exclusion criteria were as follows: people with underlying comorbidity with cardiovascular, pulmonary and neurological diseases were excluded from this study. Subjects who had taken alcoholic beverages, caffeine or stimulation drugs for the central nervous system (CNS) within $48 \mathrm{hr}$ prior to the tests, and those with musculoskeletal disease and could not follow the protocol also were excluded (Myers et al., 2014). The demographic data of the participants (i.e., age, gender, occupation, and smoking) were collected from interviews by using the questionnaire.

\section{Measurements of blood pressure and body composition}

The volunteers were asked to abstain from taking alcoholic beverages, caffeine or CNS stimulating substances for at least $48 \mathrm{hr}$, and refrain from exercise for at least $24 \mathrm{hr}$ before the tests. They should have had neither food nor water for at least $4 \mathrm{hr}$, and abstained form diuretics for at least 7 days, and they also were asked to empty their bladder at least $30 \mathrm{~min}$ before the tests (Pereira et al., 2018). All of the subjects had their blood pressure (BP) recorded in the sitting position by using a cuff BP machine (HEM7130, Omron Healthcare Co. Ltd., Kyoto, Japan). Bioelectrical impedance analysis (HBF 375, Omron Healthcare Co. Ltd., Kyoto, Japan) was used to measure body composition (i.e., fat-free mass, body and visceral fat percentages) in a room with controlled tem- 
perature. Their hands and feet were cleaned before standing on a platform throughout the test with their arms raised and elbows extended straight out (Oshima et al., 2010).

\section{Ankle-brachial index and CAVI measurement}

All of the participants were instructed not to smoke before testing or use stimulation drugs or substances related to the autonomic nervous and cardiovascular systems such as alcohol, caffeine and energy drinks (Sun, 2013). The measurement was conducted during the morning in a temperature-controlled laboratory. Ankle-brachial index (ABI) and CAVI were assessed with a phonograph vascular screening appliance (VS-1500N, Fukuda Denshi Co. Ltd., Tokyo, Japan), and electrocardiogram (ECG) and arm and leg BP cuffs. All of the participants rested and laid down for measuring the leg and arm BP simultaneously throughout the test. The ABI and CAVI were calculated from pulse wave velocity through recording from the ECG and phonocardiogram. The nature and possible consequences of the procedure for CAVI measurement was performed by a qualified cardiothoracic technologist by following the manufacturer's instructions throughout the project (Sun, 2013).

\section{Respiratory muscle strength testing}

The participants were familiarized with the instrument and procedure before the actual test. Maximal inspiratory pressure (MIP) and maximal expiratory pressure (MEP) were measured by an electronic pressure transducer (MicroRPM, Micromedical Ltd., Kent, UK) according to the American Thoracic Society/European Respiratory Society statement on respiratory muscle testing (American Thoracic Society/European Respiratory Society, 2002). The MIP was assessed from residual volume, while the MEP started from total lung capacity, according to Black and Hyatt (1969). The test was performed at least 3 times, and accomplished with a maximum of five maneuvers. The highest value among the measurements was chosen for analysis and compared with the reference value.

\section{Maximum oxygen consumption test}

The pre-test criteria for exercise and vital signs were considered before the experimental procedure. (Thompson et al., 2013) The participants abstained from caffeine, chocolate, alcohol and nicotine intake for $>48 \mathrm{hr}$ and also emptied their bladder completely within 30 min before the test. Maximum oxygen consumption $\left(\mathrm{VO}_{2 \max }\right)$ was measured by cycle ergometer (Monark 828E, Monark Exercise AB, Vansbro, Sweden) by following the submaximal Astrand-Ryhming test protocol, and setting the rhythm at 50 repe- titions per min. Active male participants performed initially at 1 Kilo Pond intensity (300- $450 \mathrm{kpm} / \mathrm{min}$ ) in order to maintain a heart rate (HR) of between 120 and 170 beats/min (Cink and Thomas, 1981). The HR for each stage was recorded for 6 min to determine a constant $\mathrm{HR}$ at the 56 th $\min . \mathrm{VO}_{2 \max }$ was calculated from their age factor and body weight to determined absolute $(\mathrm{L} / \mathrm{min})$ and relative $\mathrm{VO}_{2 \max }(\mathrm{mL} / \mathrm{kg} / \mathrm{min})$, respectively (Cink and Thomas, 1981).

\section{Statistical analysis}

All of the data were analyzed using SPSS ver. 17.0 (SPSS Inc., Chicago, IL, USA). The data normality was analyzed by the Shapiro-Wilk test. Comparisons among groups were conducted using the two-way analysis of variance design, which was used to test the main effects of physical activity in the groups (smokers vs. nonsmokers) and the interaction effect of physical activity between the groups.

\section{RESULTS}

\section{Physical characteristics of the participants}

Table 1 shows the demographic characteristics of the participants in the active and inactive smoking groups ( $\mathrm{n}=12$ in each group), and the active and inactive nonsmoking groups $(\mathrm{n}=12$ in each group). The age, height, HR, systolic and diastolic BP were not statistically significant among the groups $(P>0.05)$. Results showed that the BMI and weight in smokers were lower than in the nonsmokers group $(F=6.65, P=0.013, F=5.46, P=0.024$, respectively). The current smoking duration and frequency were higher in smokers than in nonsmokers ( $F=128.57, P<0.001, F=295.95$, $P<0.001$, respectively). The data showed no effects of significant interaction on any demographic data $(P>0.05)$.

\section{Body composition, respiratory muscle strength, and aerobic capacity}

Data of body composition, respiratory muscle strength, and aerobic capacity are summarized in Table 2 . Body and visceral fat percentage were significantly different. Body fat and visceral fat percentages were significantly higher in physically inactive than in physically active males $(F=28.87, P=0.001, F=6.99, P=0.011$, respectively) and in smokers compared to nonsmokers $(F=22.46$, $P=0.001, F=5.51, P=0.024$, . . The main effect of smoking showed no significant difference in fat-free mass $(F=0.051, P=0.822$ ), but the main effects of physical inactivity exhibited a significant difference. Fat-free mass was significantly higher in physically active 
Table 1. General characteristics of the participants

\begin{tabular}{|c|c|c|c|c|c|c|c|}
\hline \multirow{2}{*}{ Parameter } & \multirow{2}{*}{$\begin{array}{c}\text { Active } \\
\text { nonsmokers }\end{array}$} & \multirow{2}{*}{$\begin{array}{c}\text { Inactive } \\
\text { nonsmokers }\end{array}$} & \multirow{2}{*}{$\begin{array}{c}\text { Active } \\
\text { smokers }\end{array}$} & \multirow{2}{*}{$\begin{array}{l}\text { Inactive } \\
\text { smokers }\end{array}$} & \multicolumn{3}{|c|}{$P$-value } \\
\hline & & & & & Physical activity & Smoking & Interaction \\
\hline Age (yr) & $24.42 \pm 4.03$ & $25.08 \pm 4.01$ & $25.67 \pm 4.05$ & $24.25 \pm 4.20$ & 0.186 & 0.812 & 0.443 \\
\hline Height (cm) & $170.86 \pm 5.06$ & $169.92 \pm 5.40$ & $171.42 \pm 5.70$ & $168.83 \pm 5.49$ & 0.264 & 0.863 & 0.606 \\
\hline Weight (kg) & $64.69 \pm 4.31$ & $64.05 \pm 4.80$ & $62.44 \pm 4.32$ & $61.12 \pm 4.60$ & 0.558 & 0.024 & 0.713 \\
\hline $\mathrm{BMI}\left(\mathrm{kg} / \mathrm{m}^{2}\right)$ & $22.13 \pm 0.65$ & $22.15 \pm 0.72$ & $21.27 \pm 1.50$ & $21.43 \pm 1.15$ & 0.775 & 0.013 & 0.814 \\
\hline $\mathrm{HR}$ (BPM) & $69.83 \pm 6.04$ & $73.83 \pm 7.57$ & $71.75 \pm 6.32$ & $73.25 \pm 6.58$ & 0.159 & 0.730 & 0.519 \\
\hline $\mathrm{SBP}(\mathrm{mmHg})$ & $106.92 \pm 9.87$ & $108.08 \pm 8.86$ & $105.92 \pm 7.80$ & $106.42 \pm 9.66$ & 0.752 & 0.614 & 0.899 \\
\hline $\mathrm{DBP}(\mathrm{mmHg})$ & $68.58 \pm 6.20$ & $69.92 \pm 4.68$ & $69.25 \pm 4.20$ & $70.08 \pm 5.47$ & 0.417 & 0.594 & 0.933 \\
\hline \multicolumn{8}{|l|}{ Smoking measures } \\
\hline Smoking duration (yr) & $0.00 \pm 0.00$ & $0.00 \pm 0.00$ & $8.33 \pm 3.82$ & $7.92 \pm 3.45$ & 0.727 & $<0.001$ & 0.727 \\
\hline Current smoking frequency (cigarettes/day) & $0.00 \pm 0.00$ & $0.00 \pm 0.00$ & $11.87 \pm 3.56$ & $12.13 \pm 3.83$ & 0.764 & $<0.001$ & 0.764 \\
\hline \multicolumn{8}{|l|}{ Physical activity } \\
\hline Moderate & $7(58.33)$ & $7(58.33)$ & $6(50.00)$ & $8(66.67)$ & & & \\
\hline Vigorous & $5(41.67)$ & $5(41.67)$ & $6(50.00)$ & $4(33.33)$ & & & \\
\hline
\end{tabular}

Values are presented as mean \pm standard deviation or number (\%).

$\mathrm{BMI}$, body mass index; HR, heart rate; BPM, beats per min; SBP, systolic blood pressure; DBP, diastolic blood pressure; mmHg, millimeter of mercury.

Table 2. The result for body composition

\begin{tabular}{|c|c|c|c|c|c|c|c|}
\hline \multirow{2}{*}{ Parameter } & \multirow{2}{*}{$\begin{array}{c}\text { Active } \\
\text { nonsmokers }\end{array}$} & \multirow{2}{*}{$\begin{array}{c}\text { Inactive } \\
\text { nonsmokers }\end{array}$} & \multirow{2}{*}{$\begin{array}{c}\text { Active } \\
\text { smokers }\end{array}$} & \multirow{2}{*}{$\begin{array}{l}\text { Inactive } \\
\text { smokers }\end{array}$} & \multicolumn{3}{|c|}{$P$-value } \\
\hline & & & & & Physical activity & Smoking & Interaction \\
\hline $\operatorname{TBF}(\%)$ & $14.95 \pm 3.23$ & $17.49 \pm 3.06$ & $16.34 \pm 3.42$ & $24.27 \pm 3.26$ & 0.001 & 0.001 & 0.012 \\
\hline $\operatorname{VF}(\%)$ & $4.74 \pm 2.60$ & $7.14 \pm 2.20$ & $6.19 \pm 3.53$ & $9.47 \pm 3.06$ & 0.011 & 0.024 & 0.444 \\
\hline FFM (\%) & $34.33 \pm 3.89$ & $32.02 \pm 3.48$ & $34.71 \pm 3.35$ & $30.17 \pm 3.51$ & 0.007 & 0.822 & 0.554 \\
\hline
\end{tabular}

Values are presented as mean \pm standard deviation.

TBF, total body fat; VF, visceral fat; FFM, fat-free mass.

Table 3. The result for respiratory muscle strength and aerobic capacity

\begin{tabular}{|c|c|c|c|c|c|c|c|}
\hline \multirow{2}{*}{ Parameter } & \multirow{2}{*}{$\begin{array}{c}\text { Active } \\
\text { nonsmokers }\end{array}$} & \multirow{2}{*}{$\begin{array}{c}\text { Inactive } \\
\text { nonsmokers }\end{array}$} & \multirow{2}{*}{$\begin{array}{c}\text { Active } \\
\text { smokers }\end{array}$} & \multirow{2}{*}{$\begin{array}{l}\text { Inactive } \\
\text { smokers }\end{array}$} & \multicolumn{3}{|c|}{$P$-value } \\
\hline & & & & & Physical activity & Smoking & Interaction \\
\hline MIP & $101.42 \pm 14.48$ & $90.42 \pm 12.21$ & $90.08 \pm 12.27$ & $83.67 \pm 11.98$ & 0.023 & 0.018 & 0.537 \\
\hline MEP & $108.08 \pm 12.87$ & $95.66 \pm 10.81$ & $96.41 \pm 16.38$ & $90.83 \pm 12.02$ & 0.031 & 0.026 & 0.447 \\
\hline $\mathrm{VO}_{2 \max }(\mathrm{mL} / \mathrm{kg} / \mathrm{min})$ & $51.48 \pm 9.03$ & $43.33 \pm 7.39$ & $47.67 \pm 9.38$ & $33.92 \pm 6.87$ & 0.001 & 0.007 & 0.237 \\
\hline
\end{tabular}

Values are presented as mean \pm standard deviation.

$\mathrm{MIP}$, maximal inspiratory pressure; $\mathrm{MEP}$, maximal expiratory pressure; $\mathrm{VO}_{2 \text { max }}$, maximal oxygen consumption.

than in physically inactive males $(F=8.01, P=0.007)$.

In addition, the results showed a significant difference in the interaction of body fat percentage $(F=6.835, P=0.012)$, but not in the interaction of fat-free mass $(F=0.356, P=0.554)$ or visceral fat $(F=0.597, P=0.444)$. Physical activity and smoking showed a significant main effect, with $\mathrm{VO}_{2 \max }$, MIP and MEP in the physically active group being significantly higher than in the inactive group $(F=21.929, P=0.001, F=5.577, P=0.023, F=4.993, P=$ $0.031)$ and also in the smoking group compared with the nonsmoker group $(F=7.975, P=0.007, F=6.012, P=0.018, F=5.291$,
$P=0.026)$. There were no effects of interaction between physical inactivity and smoking on $\mathrm{VO}_{2 \max }(F=1.435, P=0.237)$, MIP or $\operatorname{MEP}(F=0.386, P=0.537, F=0.588, P=0.447$, respectively) (Table 3).

\section{CAVI and $A B I$}

Data on the CAVI and ABI are shown in Table 4. Mean CAVI was significantly higher in the physically inactive $(F=21.375, P=$ $0.001)$ and smoking group $(F=20.320, P=0.001)$, whereas, $\mathrm{ABI}$ was not observed as significantly different in smokers $(F=0.256$, 
Table 4. The result for cardio-ankle vascular index (CAVI) and ankle-brachial index (ABI)

\begin{tabular}{|c|c|c|c|c|c|c|c|}
\hline \multirow{2}{*}{ Parameter } & \multirow{2}{*}{$\begin{array}{c}\text { Active } \\
\text { nonsmokers }\end{array}$} & \multirow{2}{*}{$\begin{array}{c}\text { Inactive } \\
\text { nonsmokers }\end{array}$} & \multirow{2}{*}{$\begin{array}{l}\text { Active } \\
\text { smokers }\end{array}$} & \multirow{2}{*}{$\begin{array}{l}\text { Inactive } \\
\text { smokers }\end{array}$} & \multicolumn{3}{|c|}{$P$-value } \\
\hline & & & & & Physical activity & Smoking & Interaction \\
\hline \multicolumn{8}{|l|}{ CAVI } \\
\hline Right & $6.57 \pm 0.26$ & $6.83 \pm 0.29$ & $6.71 \pm 0.37$ & $7.53 \pm 0.22$ & 0.001 & 0.001 & 0.023 \\
\hline Left & $6.55 \pm 0.25$ & $6.82 \pm 0.27$ & $6.72 \pm 0.36$ & $7.55 \pm 0.25$ & 0.001 & 0.001 & 0.024 \\
\hline Mean & $6.56 \pm 0.25$ & $6.82 \pm 0.28$ & $6.72 \pm 0.37$ & $7.53 \pm 0.23$ & 0.001 & 0.001 & 0.021 \\
\hline \multicolumn{8}{|l|}{$\mathrm{ABI}$} \\
\hline Right & $1.01 \pm 0.07$ & $1.04 \pm 0.10$ & $1.02 \pm 0.07$ & $1.01 \pm 0.08$ & 0.565 & 0.693 & 0.596 \\
\hline Left & $1.01 \pm 0.08$ & $1.04 \pm 0.10$ & $1.01 \pm 0.08$ & $1.01 \pm 0.08$ & 0.465 & 0.567 & 0.546 \\
\hline Mean & $1.01 \pm 0.08$ & $1.04 \pm 0.11$ & $1.02 \pm 0.08$ & $1.01 \pm 0.08$ & 0.526 & 0.695 & 0.410 \\
\hline
\end{tabular}

Values are presented as mean \pm standard deviation.

$P=0.695)$ or the physically inactive group $(F=0.409, P=0.526)$. There were no effects of interaction between physical activity and smoking on $\mathrm{ABI}(F=0.693, P=0.410)$, but an interaction effect of mean CAVI was found $(F=5.718, P=0.021)$. In similarity, the right and left sides of the CAVI were significantly higher in the physically inactive $(F=30.38, P=0.001, F=30.98, P=0.001)$ and smoking group $(F=33.722, P=0.001, F=37.849, P=0.001)$, but a significant difference in the right and left side of $A B I$ values was not observed in smokers ( $F=0.298, P=0.693, F=0.333, P=0.567$ ) or the physically inactive group $(F=0.337, P=0.565, F=0.543$, $P=0.465)$. The result showed interaction on the right and left sides of the CAVI $(F=5.580, P=0.023, F=5.493, P=0.024)$, but did not find interaction on both sides of the $\mathrm{ABI}(F=0.243, P=0.596$, $F=0.341, P=0.546$, respectively).

\section{DISCUSSION}

The findings from this study demonstrate that smoking and physically inactive participants exhibited an imbalance of body composition through increased body fat, visceral fat percentage and increased AS by increased CAVI, while ABI was not significantly different among the groups. Fat-free mass in physically inactive participants was lower than in the physically active group. Respiratory muscle and $\mathrm{VO}_{2 \max }$ were diminished by smoking and physical inactivity. This study also found the effects of interaction between physical inactivity and smoking on body fat and CAVI.

CAVI has been a noninvasive approach to the assessment of AS and predictor risk of CVD in high-risk patients (Sun, 2013). This study found that CAVI in all of the participants was at a healthy level, with a cutoff point of less than $9 \%$, and an increase of CAVI in smokers associated with AS (Horta et al., 2015). These results are consistent with a previous study by Mahmud and Feely) (2003). that showed peripheral arterial function declining in young moderate smokers. The atherosclerotic process in younger adults, however, may progress without any major symptoms or can even be asymptomatic (Toth, 2008). Harmful substance in tobacco contributes to decreased arterial elasticity, and smoking causes increased risk of AS associated with increased BP in smokers (Mahmud and Feely, 2003).

Furthermore, inactive participants conversely increased the risk of AS by increasing CAVI, suggesting that physical inactivity is a risk factor in increasing AS in early adulthood (Horta et al., 2015). To the authors' knowledge, a significant difference was shown in the effects of interaction between BF percentage and the CAVI. The result suggested that accommodating fat could be considered a risk factor for vascular problems (Poirier et al., 2006). This study did not find a significant difference of $A B I$ in smokers and physically inactive people. The unchanged ABI was due to studying younger healthy individuals, without underlying diseases, but it may not be relevant to a clinical study. This effect would be under represented by changes in the ABI (Wassel et al., 2016).

Physical fitness is considered as a marker of health and physical performance in daily life (Dwyer et al., 2009). This study found that $\mathrm{VO}_{2 \max }$ decreased in smokers and the physically inactive group, as function of the respiratory muscles plays an important role in pulmonary ventilation. Inspiratory muscle strength that decreased in the physically inactive and smoking participants was associated with increased visceral fat. Previous study demonstrated that excess fat tissue on the thorax, which causes mechanical disadvantage, decreased diaphragmatic movement, and increased respiratory workload and ineffective biomechanics to the consequent respiratory muscle (Chlif et al., 2009; Mafort et al., 2016). This study was conducted in physically inactive participants and smokers with normal weight, but higher body and visceral fat mass, who exhib- 
ited inspiratory muscle decline, which suggested that participants of normal weight, but accommodating fat from smoking and physically inactive behavior, are at risk of respiratory muscle impairment (Scano et al., 2009). Physical inactivity is as harmful as smoking on body composition, and exercise performance (King, 2012).

Shift in environment, participating with new friends and society causes younger adults to try smoking and they can progress to chronic smokers in the future, especially when some of them believe that smoking helps to control their weight (Tombor et al., 2015; Chiolero et al., 2008). This study also showed that smoking had major effects on BMI and weight, as smokers had lower weight and BMI than nonsmokers. Even though participants with normal weight performed appropriate exercise, smoking exerted an imbalance in body composition by increasing fat mass and declining exercise performance, with increased risk of CVD (Lavie et al., 2019). Good vascular health improves working capacity and plays an important role in the prevention of CVD (Nystoriak and Bhatnagar, 2018). This study represents the overall routine of physical testing, cardiovascular checking is essential in health promotion of physical performance in younger adults (Wallace et al., 2014), persuading them to perceive their health through stopping tobacco smoking and controlling body fat by appropriate exercise rather than controlling their weight by smoking.

There are some limitations in this study. The small sample size could have affected the interaction outcomes. It is therefore suggested that further studies with larger sample sizes be conducted, using a prospective cohort study. This study did not explain the pathophysiological mechanisms of smoking or AS. Further study is needed to explain these mechanisms.

In summary, the results of this study suggest that healthy normal weight participants who not only exercise, but also smoke, can be at risk of CAD, respiratory and physical fitness decline. This study highlights the importance of appropriate physical activity and cigarette cessation in younger adults before they become addicted and adopt smoking in order to control their weight.

\section{CONFLICT OF INTEREST}

No potential conflict of interest relevant to this article was reported.

\section{ACKNOWLEDGMENTS}

This study was supported financially by a grant from the Faculty of Allied Health Sciences, Naresuan University, Thailand. The authors also gratefully acknowledge the participants in this study.

\section{REFERENCES}

American Thoracic Society/European Respiratory Society. ATS/ERS Statement on respiratory muscle testing. Am J Respir Crit Care Med 2002; 166:518-624.

Black LF, Hyatt RE. Maximal respiratory pressures: normal values and relationship to age and sex. Am Rev Respir Dis 1969;99:696-702.

Chiolero A, Faeh D, Paccaud F, Cornuz J. Consequences of smoking for body weight, body fat distribution, and insulin resistance. Am J Clin Nutr 2008;87:801-809.

Chlif M, Keochkerian D, Choquet D, Vaidie A, Ahmaidi S. Effects of obesity on breathing pattern, ventilatory neural drive and mechanics. Respir Physiol Neurobiol 2009;168:198-202.

Cink RE, Thomas TR. Validity of the Astrand-Ryhming nomogram for predicting maximal oxygen intake. Br J Sports Med 1981;15:182-185.

Dwyer T, Magnussen CG, Schmidt MD, Ukoumunne OC, Ponsonby AL, Raitakari OT, Zimmet PZ, Blair SN, Thomson R, Cleland VJ, Venn A. Decline in physical fitness from childhood to adulthood associated with increased obesity and insulin resistance in adults. Diabetes Care 2009;32:683-687.

Frech A. Pathways to adulthood and changes in health-promoting behaviors. Adv Life Course Res 2014;19:40-49.

Fu H, Feng D, Tang S, He Z, Xiang Y, Wu T, Wang R, Shao T, Liu C, Shao $\mathrm{P}$, Feng Z. Prevalence of tobacco smoking and determinants of success in quitting smoking among patients with chronic diseases: a cross-sectional study in rural Western China. Int J Environ Res Public Health 2017;14(2):E167.

Hautala AJ, Kiviniemi AM, Tulppo MP. Individual responses to aerobic exercise: the role of the autonomic nervous system. Neurosci Biobehav Rev 2009;33:107-115.

Horta BL, Schaan BD, Bielemann RM, Vianna CÁ, Gigante DP, Barros FC, Ekelund U, Hallal PC. Objectively measured physical activity and sedentary-time are associated with arterial stiffness in Brazilian young adults. Atherosclerosis 2015;243:148-154.

King A. Public health: health risks of physical inactivity similar to smoking. Nat Rev Cardiol 2012;9:492.

Lavie CJ, Ozemek C, Carbone S, Katzmarzyk PT, Blair SN. Sedentary behavior, exercise, and cardiovascular Health. Circ Res 2019;124:799-815.

Lee PH, Macfarlane DJ, Lam TH, Stewart SM. Validity of the International Physical Activity Questionnaire Short Form (IPAQ-SF): a systematic review. Int J Behav Nutr Phys Act 2011;8:115.

Mafort TT, Rufino R, Costa CH, Lopes AJ. Obesity: systemic and pulmonary complications, biochemical abnormalities, and impairment of 
lung function. Multidiscip Respir Med 2016;11:28.

Mahmud A, Feely J. Effect of smoking on arterial stiffness and pulse pressure amplification. Hypertension 2003;41:183-187.

Mainous AG 3rd, Tanner RJ, Rahmanian KP, Jo A, Carek PJ. Effect of sedentary lifestyle on cardiovascular disease risk among healthy adults with body mass indexes 18.5 to $29.9 \mathrm{~kg} / \mathrm{m}^{2}$. Am J Cardiol 2019;123: 764-768.

Mucci N, Giorgi G, Roncaioli M, Fiz Perez J, Arcangeli G. The correlation between stress and economic crisis: a systematic review. Neuropsychiatr Dis Treat 2016;12:983-993.

Myers J, Forman DE, Balady GJ, Franklin BA, Nelson-Worel J, Martin BJ, Herbert WG, Guazzi M, Arena R; American Heart Association Subcommittee on Exercise, Cardiac Rehabilitation, and Prevention of the Council on Clinical Cardiology, Council on Lifestyle and Cardiometabolic Health, Council on Epidemiology and Prevention, and Council on Cardiovascular and Stroke Nursing. Supervision of exercise testing by nonphysicians: a scientific statement from the American Heart Association. Circulation 2014;130:1014-1027.

Nystoriak MA, Bhatnagar A. Cardiovascular effects and benefits of exercise. Front Cardiovasc Med 2018;5:135.

Oja P, Titze S. Physical activity recommendations for public health: development and policy context. EPMA J 2011;2:253-259.

Oshima Y, Shiga T, Namba H, Kuno S. Estimation of whole-body skeletal muscle mass by bioelectrical impedance analysis in the standing position. Obes Res Clin Pract 2010;4:e1-82.

Pereira C, Silva RAD, de Oliveira MR, Souza RDN, Borges RJ, Vieira ER. Effect of body mass index and fat mass on balance force platform measurements during a one-legged stance in older adults. Aging Clin Exp Res 2018;30:441-447.

Poirier P, Giles TD, Bray GA, Hong Y, Stern JS, Pi-Sunyer FX, Eckel RH. Obesity and cardiovascular disease: pathophysiology, evaluation, and effect of weight loss. Arterioscler Thromb Vasc Biol 2006;26:968-976.

Pulvers K, Scheuermann TS, Romero DR, Basora B, Luo X, Ahluwalia JS. Classifying a smoker scale in adult daily and nondaily smokers. Nicotine Tob Res 2014;16:591-599.

Scano G, Stendardi L, Bruni GI. The respiratory muscles in eucapnic obe- sity: their role in dyspnea. Respir Med 2009;103:1276-1285.

Sullivan AN, Lachman ME. Behavior change with fitness technology in sedentary adults: a review of the evidence for increasing physical activity. Front Public Health 2017;4:289.

Sun CK. Cardio-ankle vascular index (CAVI) as an indicator of arterial stiffness. Integr Blood Press Control 2013;6:27-38.

Thitiwuthikiat $\mathrm{P}$, Jongitwimol J, Nuamchit T. Positive relationship between smoking and the arterial stiffness index in adults without underlying diseases. Songkla Med J 2017;35:159-168.

Thompson PD, Arena R, Riebe D, Pescatello LS; American College of Sports Medicine. ACSM's new preparticipation health screening recommendations from ACSM's guidelines for exercise testing and prescription, ninth edition. Curr Sports Med Rep 2013;12:215-217.

Tombor I, Shahab L, Herbec A, Neale J, Michie S, West R. Smoker identity and its potential role in young adults' smoking behavior: a meta-ethnography. Health Psychol 2015;34:992-1003.

Toth PP. Subclinical atherosclerosis: what it is, what it means and what we can do about it. Int J Clin Pract 2008;62:1246-1254.

van der Palen J, Rea TD, Manolio TA, Lumley T, Newman AB, Tracy RP, Enright PL, Psaty BM. Respiratory muscle strength and the risk of incident cardiovascular events. Thorax 2004;59:1063-1067.

Wallace ML, Ricco JA, Barrett B. Screening strategies for cardiovascular disease in asymptomatic adults. Prim Care 2014;41:371-397.

Wassel CL, Allison MA, Ix JH, Rifkin DE, Forbang NI, Denenberg JO, Criqui MH. Ankle-brachial index predicts change over time in functional status in the San Diego Population Study. J Vasc Surg 2016;64: 656-662.e1.

Wee CC, Rigotti NA, Davis RB, Phillips RS. Relationship between smoking and weight control efforts among adults in the united states. Arch Intern Med 2001;161:546-550.

Yadav RL, Yadav PK, Yadav LK, Agrawal K, Sah SK, Islam MN. Association between obesity and heart rate variability indices: an intuition toward cardiac autonomic alteration - a risk of CVD. Diabetes Metab Syndr Obes 2017;10:57-64. 